Original article

Reprint

\title{
Effect of different pancreatic stump closure techniques after distal pancreatectomy on frequency and severity of acute postoperative pancreatitis
}

\author{
Sergei E. Voskanyan ${ }^{1}$, Evgeny V. Naydenov ${ }^{1}$, Igor Yu. Uteshev ${ }^{1}$, Aleksei I. Artemiev ${ }^{1}$
}

${ }^{1}$ A.I. Burnazyan Federal Medical Biophysical Center at Russian Federation Medical Biological Agency

Received 21 March, 2018, Accepted 21 January, 2020

Original Text (C) Voskanyan S.E., Naydenov E.V., Uteshev I.Yu., Artemiev A.I., 2018, published in Saratov Journal of Medical Scientific Research 2018; 14 (2): 260-265

(C) 2020, Voskanyan S.E., Naydenov E.V., Uteshev I.Yu., Artemiev A.I.

(C) 2020, Saratov Medical Journal

\begin{abstract}
:
Objective: to study the effect of different pancreatic stump closure techniques and diameter of the main pancreatic duct on frequency and severity of acute postoperative pancreatitis after distal pancreatectomy.

Material and Methods. Distal pancreatectomy was performed on 126 patients with neoplasms of body and/or tail of the pancreas. Patients were distributed among four groups based upon the pancreatic stump closure technique applied after distal pancreatectomy: group 1 (control) included the patients with isolated suturing of the main pancreatic duct in the pancreatic stump with its subsequent sealing by the gastrocolic omentum or hemostatic sponge; group 2 patients underwent isolated suturing of the main pancreatic duct in the pancreatic stump with its subsequent sealing with 2-octyl cyanoacrylate biological glue; group 3 patients had their pancreatic stump closure performed with endoscopic linear cutter stapler; group 4 was composed of the patients with external transduodenal transnasal drainage of enlarged ( $>3 \mathrm{~mm})$ main pancreatic duct in the pancreatic stump.

Results. The occurrence of acute postoperative pancreatitis in the control group amounted to $45.8 \%$, while, in groups 2,3 and 4 , the frequencies were 44.4, 9.7 and $15.0(\%)$, correspondingly. Besides, the control group was characterized by declined occurrence of the moderately severe form of acute postoperative pancreatitis. Use of endoscopic linear cutter stapler and external transduodenal transnasal drainage of the enlarged main pancreatic duct caused lower acute postoperative pancreatitis frequency in the patients with main pancreatic duct in their pancreatic stumps below $5 \mathrm{~mm}$ in diameter.

Conclusion. Use of proposed pancreatic stump closure techniques after distal pancreatectomy resulted in lower frequencies of occurrence and severity of acute postoperative pancreatitis.
\end{abstract}

Keywords: pancreas, distal pancreatectomy, pancreatic tumors, acute postoperative pancreatitis.

Cite as Voskanyan SE, Naydenov EV, Uteshev IYu, Artemiev AI. Effect of different pancreatic stump closure techniques after distal pancreatectomy on frequency and severity of acute postoperative pancreatitis. Saratov Medical Journal 2020; 1(1): e0104.

Correspondence to Evgeny V. Naydenov. Tel.: +7-499-199-95-61; +7-905-789-79-25. E-mail: e.v.naydenov@mail.ru.

\section{Introduction}

Currently we observe an expansion of medical indications for organ-preserving interventions on pancreas in the patients with malignant and neuroendocrine neoplasms, cystic tumors and chronic pancreatitis [1].

Corporeo-caudal, or distal, pancreatectomies make up nearly one-third of all cases of pancreatic surgeries [2, 3]. They are performed because of malignant neoplasms, endocrine or intraductal mucinous neoplasms, pseudocysts and cystic lesions, limited parenchymal damage caused by destructive pancreatitis, chronic pancreatitis, metastatic spread from other tumors, pancreatic trauma with ductal injury [4], and corporeo-caudal involvement in locally advanced tumors of adjacent organs (stomach, colon).

The most common and severe postoperative complication of pancreatic surgery is acute postoperative pancreatitis (APP): according to the published studies, its frequency of occurrence in the patients may achieve up to 50-100\% [5-12].
The main clinical manifestations of APP include the dehiscence of pancreatic anastomoses or pancreatic stump, formation of pancreatic fistulae, abdominal and retroperitoneal abscesses, hemorrhages due to blood vessel erosion, and impairment of gastric emptying function. All of the above are the main causes of prolonged hospital stay and in-hospital patient mortality after the pancreatic surgeries [614].

Incidence of postoperative complications after distal pancreatic resection remains high and may achieve 60\% [2, 15]. It is worth noting that use of various techniques to close and seal the pancreatic stump, as well as intake of somatostatin and its analogues shows no benefit in terms of preventing such complications [15]. Hence, the relevance of developing new techniques of closing and sealing proximal pancreatic stumps after distal pancreatectomy in order to prevent APP at the postoperative stage of the patient treatment is very high. 
Objective: to study the effects of a diameter of main pancreatic duct and various techniques of closing and sealing the pancreatic stump after the distal pancreatectomy on occurrence and severity of APP.

\section{Material and methods}

From January 2010 through December 2017, we treated 126 patients with malignant or benign neoplasms of pancreatic body and/or tail, or with locally advanced stomach or colon cancer invading the body/tail of their pancreas. All patients underwent corporeo-caudal (distal) pancreatectomy: spleen-sparing corporeo-caudal pancreatectomy, distal pancreatectomy with splenectomy, distal pancreatectomy with a gastric surgery (such as gastrectomy or proximal gastric resection), or corporeo-caudal pancreatomy combined with a radical colon surgery (transverse colon resection, left hemicolectomy). Among those, 29 patients (23.0\%) underwent laparoscopy and 97 patients (77.0\%) underwent open surgery.

Patients were 20 to 86 years old, $54.8 \%$ of them were 2160 years old (employment age). Male to female ratio was $51: 75$.

Depending on technique of resection and pancreatic stump closure after distal pancreatectomy, all patients were divided into four groups.

Group 1 (control group) consisted of 48 patients who underwent isolated suturing of main pancreatic duct with subsequent stump closure by a greater omentum patch (subgroup 1.1; $\mathrm{n}=28$ ), or by means of local sealing with a hemostatic sponge (subgroup 1.2; $\mathrm{n}=20$ ).

Group 2 consisted of 27 patients who underwent isolated suturing of main pancreatic duct with subsequent local sealing with 2-octyl cyanoacrylate biological glue (DermabondTM).

Group 3 patients $(n=31)$ had corporeo-caudal pancreatectomies with stump closure performed using an EchelonTM cutter/stapler device (Ethicon Endo-Surgery, Inc.).

Group 4 consisted of 20 patients with enlarged main pancreatic duct (over $3 \mathrm{~mm}$ in diameter), who underwent distal pancreatectomy with external transduodenal transnasal drainage of a main pancreatic duct. The latter was subsequently sutured.

According to the principles of perioperative risk prediction $[11,16]$, all patients were evaluated for the presence of APP risk factors and then stratified into two groups, corresponding to a high vs. moderate risk of APP (Table 1).

We studied the effects of main pancreatic duct diameter and different techniques of pancreatic stump closure after corporeo-caudal pancreatectomy on APP frequencies of occurrence (Table 2).

Perioperative prevention of APP was attempted in accordance with original algorithms $[6-8,11]$. Patient groups were compatible in terms of conservative preventive measures used to avoid APP after distal pancreatectomy.

To study the direct results of surgical treatment, all patients were evaluated twice: early in the postoperative period and at the time of their discharge from the hospital.

Clinical, laboratory and imaging criteria for APP were studied and assessed by the complication severity grading system proposed by our team $[6,11]$.
Table 1. Stratification of the patients by the risk value of APP

\begin{tabular}{|c|c|c|c|}
\hline \multirow{2}{*}{ Patient groups } & \multicolumn{3}{|c|}{ APP risk level } \\
\hline \multirow{2}{*}{ Group 1 (n=48) } & Moderate APP risk & \multicolumn{2}{|c|}{ High APP risk } \\
\hline \multirow{2}{*}{ Subgroup 1.1 (n=28) } & abs. & 15 & 33 \\
\hline Subgroup 1.2 (n=20) & abs. & $31.25 \%$ & $68.75 \%$ \\
\hline Group 2 (n=27) & $\%$ & $32.1 \%$ & $67.9 \%$ \\
\hline \multirow{2}{*}{ Group 3 (n=31) } & abs. & 6 & 14 \\
\hline \multirow{2}{*}{ Group 4 (n=20) } & abs. & $70.0 \%$ & $70.0 \%$ \\
\hline \multirow{2}{*}{ Total } & $\%$ & $25.9 \%$ & $74.1 \%$ \\
\hline & abs. & 9 & 22 \\
\hline
\end{tabular}

Differences among the patient groups were not statistically significant (chi-square test); abs. - absolute numbers

Table 2. Patient numbers vs. main pancreatic duct diameter of a pancreatic stump

\begin{tabular}{|c|c|c|c|c|}
\hline \multirow{2}{*}{$\begin{array}{c}\text { MPD } \\
\text { diameter }\end{array}$} & Group 1 & Group 2 & Group 3 & $\begin{array}{c}\text { Group } \\
4\end{array}$ \\
\cline { 2 - 5 } & $\begin{array}{c}\mathrm{n}=48, \\
\text { abs. (\%) }\end{array}$ & $\begin{array}{c}\mathrm{n}=27, \\
\text { abs. (\%) }\end{array}$ & $\begin{array}{c}\mathrm{n}=31, \\
\text { abs. (\%) }\end{array}$ & $\begin{array}{c}\mathrm{n}=20, \\
\text { abs. } \\
(\%)\end{array}$ \\
\hline Under 3 mm & $\begin{array}{c}30 \\
(62.5 \%)^{*}\end{array}$ & $\begin{array}{c}18 \\
(66.7 \%)^{*}\end{array}$ & $\begin{array}{c}20 \\
(64.5 \%)^{*}\end{array}$ & - \\
\hline $3-5 \mathrm{~mm}$ & $\begin{array}{c}16 \\
(33.3 \%)^{*}\end{array}$ & $8(29.6 \%)^{*}$ & $\begin{array}{c}10 \\
(32.2 \%)^{*}\end{array}$ & $\begin{array}{c}17 \\
(85.0 \%)\end{array}$ \\
\hline $\begin{array}{c}5 \mathrm{~mm} \text { or } \\
\text { larger }\end{array}$ & $2(4.2 \%)$ & $1(3.7 \%)$ & $1(3.2 \%)$ & $\begin{array}{c}3 \\
(15.0 \%)\end{array}$ \\
\hline
\end{tabular}

MPD - main pancreatic duct; abs. - absolute numbers; * differences were statistically significant $(p<0.05)$ when compared with group 4.

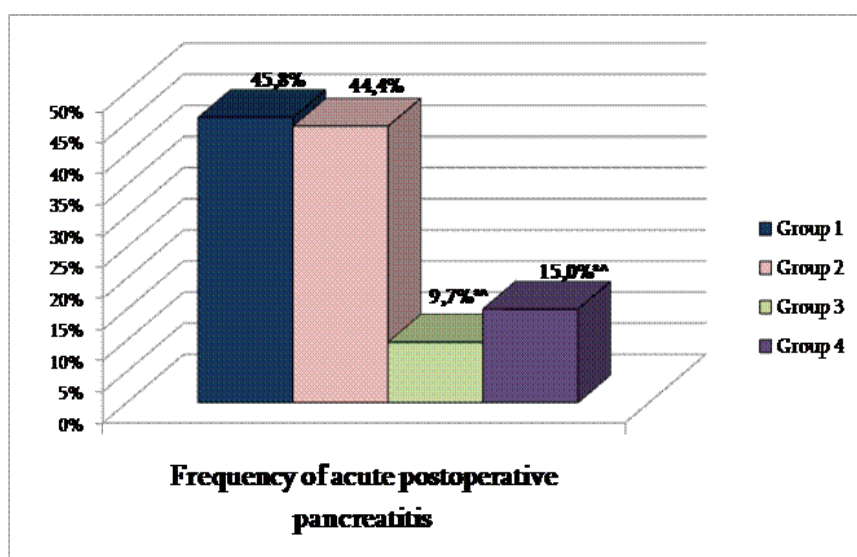

Figure 1. Effect of different techniques of pancreatic stump closure after corporeo-caudal pancreatectomy on occurrence of acute postoperative pancreatitis: * differences were statistically significant $(p<0.05)$ when compared with group 1 (chi-square test); ${ }^{\wedge}-$ differences were statistically significant $(p<0.05)$ when compared with group 2 (chi-square test). 
Statistical analysis of the data was performed using "Statistica 10.0" software (StatSoft Inc., USA) for Windows. In order to detect statistically significant differences among studied groups, we used non-parametric tests (Wilcoxon test, Kruskal-Wallis ANOVA, Mann-Whitney U-test, chi-square test) with significance threshold of p<0.05 [17].

\section{Results}

Incidence of APP after corporeo-caudal pancreatectomy with standard techniques of stump closure (control group) was $45.8 \%$ (Figure 1).

No statistically significant difference ( $p>0.05$ ) was found for occurrence of APP after corporeo-caudal pancreatectomy with a local sealing of the stump using 2-octyl cyanoacrylate (DermabondTM) (group 2) when compared with a control group; APP occurrence in group 2 patients was $44.4 \%$.

Use of a stapler/cutter device for the pancreatic stump closure after distal pancreatectomy (group 3) resulted in a statistically significant $(\mathrm{p}<0.05)$ decrease of APP occurrence when compared with a control group and group 2 patients. APP incidence in group 3 patients was 9.7\%.

Group of the patients who underwent a drainage of enlarged pancreatic duct after the distal pancreatectomy (group 4) had APP occurrence of $15.0 \%$ ( $p<0.05$ when compared with a control group and group 2 patients; $p>0.05$ when compared with group 3 patients).

Control group had no statistically significant $(\mathrm{p}>0.05)$ differences in terms of APP occurrence in the patients who underwent stump closure with omentum patch (subgroup 1.1) vs. the patients with a hemostatic sponge (subgroup 1.2) after the corporeo-caudal pancreatectomy (Table 3). APP incidence in the subgroup 1.1 was $46.4 \%$ ( $\mathrm{p}<0.05$ when compared with groups 3 and 4), while in the subgroup 1.2 it was $45.0 \%$ ( $p<0.05$ when compared with groups 3 and 4 ).

Moderately severe forms of APP were significantly less common $(\mathrm{p}<0.05)$ in groups 2,3 and 4 when compared with a control group, or with subgroups 1.1 and 1.2. Also, we observed significantly higher $(\mathrm{p}<0.05)$ occurrence of mild APP cases in group 2 patients compared with a control group, or groups 3 and 4 .

There were no severe cases of APP in groups 2, 3 and 4 .

There was no statistically significant difference ( $p>0.05$ ) for APP occurrence among the patients with a moderate risk of complications after corporeo-caudal pancreatectomies (Figure 2).

APP occurrence in the patients with a high risk of complications was $51.5 \%$ in the control group, $50.0 \%$ in group 2 ( $p>0.05$ when compared with control group), $9.1 \%$ in group 3 ( $\mathrm{p}<0.05$ when compared with control group and group 2), and $18.75 \%$ in group $4(\mathrm{p}<0.05$ when compared with control group) (Figure 3).

Incidence of APP after corporeo-caudal pancreatectomy in control group patients with main pancreatic duct diameter below $3 \mathrm{~mm}$ was $40.0 \%$, while in group 2 patients it amounted to $33.3 \%$ ( $>>0.05$ when compared with the control group) (Table 4).

The patients after corporeo-caudal pancreatectomy with MPD diameter below $3 \mathrm{~mm}$ in group 2 had significantly lower incidence of APP (5.0\%; $\mathrm{p}<0.05$ when compared with control group and group 2 patients). Also, there was a significantly $(\mathrm{p}<0.05)$ lower APP occurrence in the patients of group 3 with a pancreatic stump MPD diameter below $3 \mathrm{~mm}$ when compared with control group and group 2 patients.

APP occurrence in control group patients with MPD diameter of $3-5 \mathrm{~mm}$ was at the level of $56.3 \%$, while group 2 patients with MPD diameter of 3-5 mm had APP occurrence of $62.5 \%$ ( $p>0.05$ when compared with control group) (Table 4).

In the group 3 patients with MPD diameter equal to 3-5 $\mathrm{mm}$, we detected a statistically significant decrease in APP occurrence of $10.0 \%(\mathrm{p}<0.05$ when compared with control group and group 2 patients).

Incidence of APP in group 4 patients with MPD diameter of $3-5 \mathrm{~mm}$ was $11.8 \%$ ( $\mathrm{p}<0.05$ when compared with control group and group 2 patients).

No statistically significant difference $(\mathrm{p}>0.05)$ was found for APP occurrence in all patient groups after corporeocaudal pancreatectomies if MPD diameter was above $5 \mathrm{~mm}$ (Table 4).

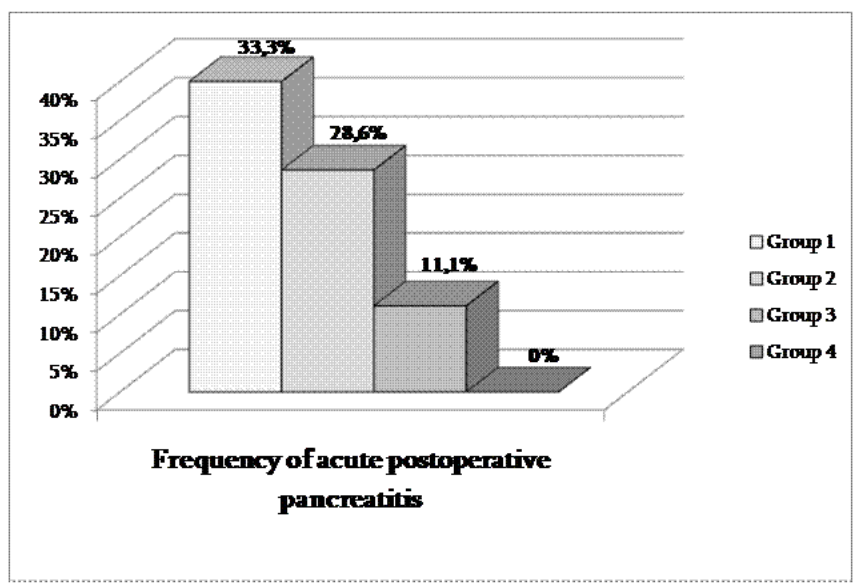

Figure 2. Effect of different techniques for pancreatic stump closure after distal pancreatectomy on occurrence of acute postoperative pancreatitis in the patients with a moderate risk of complications.

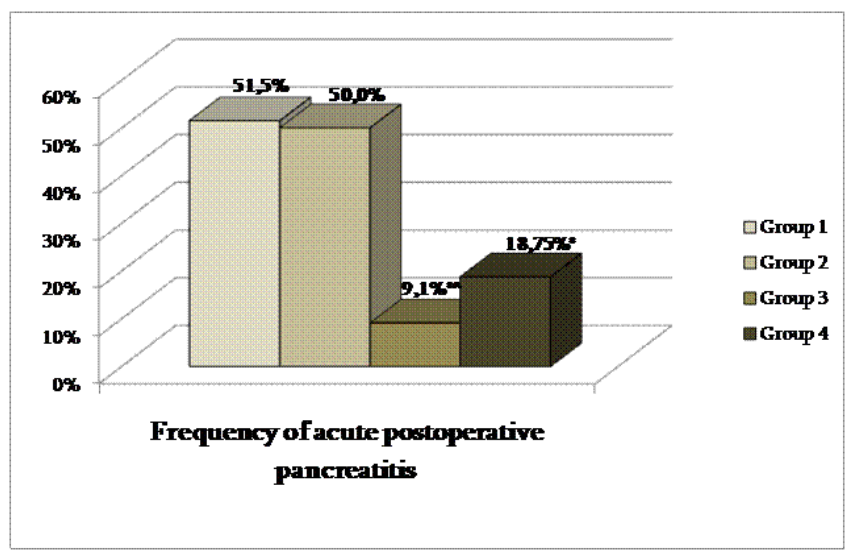

Figure 3. Effect of different techniques of pancreatic stump closure after corporeo-caudal pancreatectomy on occurrence of acute postoperative pancreatitis in the patients with a high risk of complications: ${ }^{*}$ - differences were statistically significant $(p<0.05)$ when compared with group 1 patients (chi-square test); $\wedge$ - differences were statistically significant $(p<0.05)$ when compared with $\begin{array}{llll}\text { group } 2 & 2 & \text { patients } & \\ & & \end{array}$ 
Table 3. APP after distal pancreatectomy

\begin{tabular}{|c|c|c|c|c|c|c|c|c|c|c|c|}
\hline \multirow{3}{*}{$\begin{array}{l}\text { Patient } \\
\text { groups }\end{array}$} & \multirow{3}{*}{$\begin{array}{c}\text { APP } \\
\text { occurrence } \\
\text { abs. }\end{array}$} & \multicolumn{10}{|c|}{ APP severity } \\
\hline & & \multirow{2}{*}{$\begin{array}{c}\text { mild } \\
\%\end{array}$} & \multirow{2}{*}{$\begin{array}{c}\text { moderate } \\
\text { abs. }\end{array}$} & \multicolumn{8}{|c|}{ severe } \\
\hline & & & & $\%^{1}$ & $\%^{2}$ & abs. & $\%^{1}$ & $\%{ }^{2}$ & abs. & $\%^{1}$ & $\%^{2}$ \\
\hline $\begin{array}{l}\text { Group } 1 \\
(\mathrm{n}=48)\end{array}$ & 22 & 45.8 & 6 & 27.3 & 12.5 & 15 & 68.2 & 31.3 & 1 & 4.5 & 2.1 \\
\hline $\begin{array}{l}\text { Subgroup } \\
1.1(\mathrm{n}=28)\end{array}$ & 13 & 46.4 & 3 & 23.1 & 10.7 & 9 & 69.2 & 32.1 & 1 & 8.3 & 3.8 \\
\hline $\begin{array}{l}\text { Subgroup } \\
1.2(\mathrm{n}=20)\end{array}$ & 9 & 45.0 & 3 & 33.3 & 15.0 & 6 & 66.7 & 30.0 & 0 & 0 & 0 \\
\hline $\begin{array}{l}\text { Group } 2 \\
(\mathrm{n}=27)\end{array}$ & 12 & 44.4 & 10 & $83.3^{* \wedge \circ}$ & $37.0^{* \wedge}$ & 2 & 16.6 & $7.4^{* \wedge \circ}$ & 0 & 0 & 0 \\
\hline $\begin{array}{l}\text { Group } 3 \\
(n=31)\end{array}$ & 3 & $9.7^{* \wedge \circ_{\mathrm{V}}}$ & 2 & 66.7 & $9.7^{\mathrm{v}}$ & 1 & 33.3 & $3.2^{* \wedge \circ}$ & 0 & 0 & 0 \\
\hline $\begin{array}{l}\text { Group } 4 \\
(\mathrm{n}=20)\end{array}$ & 3 & $15.0^{* \wedge \circ_{\mathrm{V}}}$ & 2 & 66.7 & $10.0^{\mathrm{v}}$ & 1 & 33.3 & $5.0^{* \wedge \circ}$ & 0 & 0 & 0 \\
\hline
\end{tabular}

APP - acute postoperative pancreatitis (classification and severity grading for APP was taken from [6, 11]; abs. - absolute numbers; \%1 - APP severity distribution among the patients with complications; \%2 - frequency of various forms of APP among all patients in a group. ${ }^{*}-$ statistically significant difference $(\mathrm{p}<0.05)$ from control group (chi-square test); ${ }^{\wedge}$ - statistically significant difference $(\mathrm{p}<0.05)$ from subgroup 1.1 (chi-square test); ${ }^{\circ}-$ statistically significant difference $(\mathrm{p}<0.05)$ from subgroup 1.2 (chi-square test); ${ }^{v}-$ statistically significant difference ( $\mathrm{p}<0.05$ ) from group 2 (chi-square test).

Table 4. Occurrence of APP after distal pancreatectomy vs. main pancreatic duct diameter in different patient groups

\begin{tabular}{|c|c|c|c|c|c|}
\hline \multirow{2}{*}{$\begin{array}{c}\text { MPD } \\
\text { diameter }\end{array}$} & \multirow{2}{*}{ Patient groups } & \multicolumn{4}{|c|}{ APP occurrence } \\
\hline & & abs. & $\%^{1}$ & $\%^{2}$ & $\%^{3}$ \\
\hline \multirow{2}{*}{$<3 \mathrm{~mm}$} & Group $1(\mathrm{n}=30)$ & 12 & 40.0 & 25.0 & 54.5 \\
\hline & Group $2(\mathrm{n}=18)$ & 6 & 33.3 & 22.2 & 50.0 \\
\hline $\begin{array}{c}\text { Group } 3 \\
(\mathrm{n}=20)\end{array}$ & & 1 & $5.0^{* \wedge}$ & $3.2^{* \wedge}$ & 33.3 \\
\hline \multirow{4}{*}{$3-5 \mathrm{~mm}$} & Group $1(\mathrm{n}=16)$ & 9 & 56.3 & 18.8 & 40.1 \\
\hline & Group $2(\mathrm{n}=8)$ & 5 & 62.5 & 18.5 & 41.2 \\
\hline & Group $3(\mathrm{n}=10)$ & 1 & $10.0^{* \wedge}$ & $3.2^{* \wedge}$ & 33.3 \\
\hline & Group $4(\mathrm{n}=17)$ & 2 & $11.8^{* \wedge}$ & 10.0 & 66.7 \\
\hline \multirow{4}{*}{$>5 \mathrm{~mm}$} & Group $1(\mathrm{n}=2)$ & 1 & 50.0 & 2.1 & 4.5 \\
\hline & Group $2(\mathrm{n}=1)$ & 1 & 100.0 & 3.7 & 8.3 \\
\hline & Group $3(\mathrm{n}=1)$ & 1 & 100.0 & 3.2 & 33.3 \\
\hline & Group $4(\mathrm{n}=3)$ & 1 & 33.3 & 5.0 & 33.3 \\
\hline
\end{tabular}

MPD - main pancreatic duct; APP - acute postoperative pancreatitis (classification and severity grading for APP were taken from [6. 11]; abs. - absolute numbers; \%1 - APP occurrence in the patients with this MPD diameter; \%2 - APP occurrence among all patients in this group; \%3 - APP proportion among all patients with APP in this group; * - differences were statistically significant $(p<0.05)$ when compared with control group patients (chi-square test); $\wedge$ differences were statistically significant $(\mathrm{p}<0.05)$ when compared with group 2 patients (chi-square test).

\section{Discussion}

Study of short-term results in the postoperative period has revealed that $45.8 \%$ of the patients who underwent distal pancreatectomy with a "conventional" technique of pancreatic stump closure develop APP, while this complication was most common in the high risk patients, according to the perioperative risk assessment $[6,11,16]$. APP cases of moderate severity prevailed.

Isolated suturing of MPD within proximal pancreatic stump followed by a local sealing of the pancreatic stump with 2-octyl cyanoacrylate biological glue (DermabondTM) after corporeo-caudal pancreatectomy had no influence on the incidence of APP among all patients, as well as among high risk patients. However, it led to a greater proportion of mild APP cases.

Using a cutter/stapler device to close the pancreatic stump after the corporeo-caudal pancreatectomy, as well as isolated suturing of MPD of a proximal pancreatic stump with subsequent transduodenal transnasal draining resulted in decreased occurrence and severity of overall APP, APP in the patients with a high risk of complications, and APP in the patients with MPD diameter above $5 \mathrm{~mm}$.

\section{Conclusion}

Using the proposed techniques of pancreatic stump closure after corporeo-caudal pancreatomy led to a decrease in occurrence and severity of an acute postoperative pancreatitis.

Conflict of interest: none stated. 


\section{References}

1. Lyadov VK. Novozhilov NV. Drug therapy after operations on the pancreas. Poliklinika 2015; 1(1): 21-5.

2. Ejaz A, Sachs T, He J, et al. A comparison of open and minimally invasive surgery for hepatic and pancreatic resections using the Nationwide Inpatient Sample. Surgery 2014; 156: 538-47. http://dx.doi.org/10.1016/j.surg.2014.03.046

3. Justin V, Fingerhut A, Khatkov I, et al. Laparoscopic pancreatic resection: a review. Transl Gastroenterol Hepatol 2016; 1: 36. http://dx.doi.org/10.21037/tgh.2016.04.02

4. Mehrabi A, Hafezi M, Arvin J, et al. A systematic review and meta-analysis of laparoscopic versus open distal pancreatectomy for benign and malignant lesions of the pancreas: it's time to randomize. Surgery 2015; 157(1): 45-55. http://dx.doi.org/10.1016/j.surg.2014.06.081

5. Onopriev VI, Korot'ko GF, Rogal VL, et al. Pancreatoduodenectomy (aspects of the surgical technique. the functional consequences). Krasnodar 2005; 135.

6. Voskanyan SE. Morphofunctional organization of the pancreas and clinical-experimental aspects of acute postoperative pancreatitis: DSc abstract. Moscow. 2013; 48.

7. Voskanyan SE, Korsakov IN, Naydenov EV. Prophylaxis of Acute Postoperative Pancreatitis in Pancreas Cancer Surgery. Annals of $\begin{array}{llll}\text { Surgical Hepatology 2013; } 18 & \text { (2): 95-102. }\end{array}$ http://vidar.ru/Article.asp?fid=ASH $2013 \quad 2 \quad 95$

8. Voskanyan SE, Zabelin MV, Naydenov EV, et al. Results of the complex prevention of the acute postoperative pancreatitis after direct operations on the pancreas. Annals of Surgery 2015; (6): 14-9.

9. Krieger AG, Kubishkin VA, Karmazanovskiy GG, et al. The postoperative pancreatitis after the pancreatic surgery. Surgery 2012; 4: 14-9. https://www.mediasphera.ru/issues/khirurgiyazhurnal-im-n-i-pirogova/2012/4/downloads/ru/030023$\underline{1207201243}$

10. Vichuzhanin DV, Egorov AV, Levkin VV, et al. The diagnostics and prevention of the postoperative pancreatitis. Surgery 2012; 4: 63-9.

https://www.mediasphera.ru/issues/khirurgiya-zhurnal-im-n-ipirogova/2012/4/downloads/ru/030023-12072012412

11. Voskanyan SE, Korot'ko GF. Morphofunctional organization of the pancreas and acute postoperative pancreatitis (experimental and clinical aspects). Litterra 2017; 528 .

12. Laaninen M, Blauer M, Vasama K, et al. The risk for immediate postoperative complications after pancreaticoduodenectomy is increased by high frequency of acinar cells and decreased by prevalent fibrosis of the cut edge of pancreas. Pancreas 2012; 41 (6): 957-61. http://dx.doi.org/10.1097/MPA.obo13e3182480b81

13. Bassi C, Dervenis C, Butturini G, et al. for the International Study Group on Pancreatic Fistula Definition Postoperative Pancreatic Fistula: An international study group (ISGPF) definition. Surgery 2005; 138 (1): 8-13.

14. Lermite E, Sommacale D, Piardi T, et al. Complications after pancreatic resection: diagnosis. prevention and management. Clin Res Hepatol Gastroenterol 2013; 37(3): 230-9.

http://dx.doi.org/10.1016/j.clinre.2013.01.003

15. Kriger AG, Berelavichus SV, Smirnov AV, et al. Comparative results of open robot-assisted and laparoscopic distal pancreatic resection. Journal Surgery n.a. N.I. Pirogov 2015; 1: 23-9.

16. Voskanyan SE, Kotenko KV, Korsakov IN, et al. Predicting of the development of acute pancreatitis as a complication after surgery on the pancreas. Experimental and Clinical Gastroenterology 2014; 9(109): 61-8.
17. Rebrova OYu. Once Again. On the Quality of Statistical Analysis in Medical Publications: Current Status of the Problem. Recommendations. Peer Reviewing. Medical Technologies: Assessment and Choice 2014; 15(1): 8-10. https://cyberleninka.ru/article/n/i-vnov-o-kachestvestatisticheskih-aspektov-meditsinskih-publikatsiy-sostoyanieproblemy-rekomendatsii-retsenzirovanie

\section{Authors:}

Sergei E. Voskanyan - DSc, Chair of Surgery Department with courses in Surgical Oncology, Endoscopy, Surgical Pathology, Clinical Transplantation and Organ Donation taught at the Institute of Postgraduate Professional Education, Head of Surgery and Transplantation Center, A.I. Burnazyan Federal Medical Biophysical Center at Russian Federation Medical Biological Agency, Moscow, Russia;

Evgeny V. Naydenov - PhD, Practicing Surgeon at Surgery Division, Senior Research Scientist at Laboratory of Novel Surgical Technology, Surgery and Transplantation Center, A.I. Burnazyan Federal Medical Biophysical Center at Russian Federation Medical Biological Agency, Moscow, Russia;

Igor Yu. Uteshev - post-graduate student, Department of Surgery with courses in Surgical Oncology, Endoscopy, Surgical Pathology, Clinical Transplantation and Organ Donation taught at the Institute of Post-graduate Professional Education, A.I. Burnazyan Federal Medical Biophysical Center at Russian Federation Medical Biological Agency, Moscow, Russia;

Aleksei I. Artemiev - PhD, Head of Surgery Division, Surgery and Transplantation Center, A.I. Burnazyan Federal Medical Biophysical Center at Russian Federation Medical Biological Agency, Moscow, Russia. 